\title{
Electronic Games for Facilitating Social Interaction Between Parents With Cancer and Their Children During Hospitalization: Interdisciplinary Game Development
}

Karin Piil ${ }^{1,2}$, MSc, PhD; Helle Holm Gyldenvang ${ }^{1}$, BA, MSc; Jeppe Kilberg Møller ${ }^{3}$, MSc; Tine Kjoelsen ${ }^{3}$, MA; Jesper Juul ${ }^{3}$, MA, PhD; Helle Pappot ${ }^{1,4}$, MD, PhD, Prof Dr

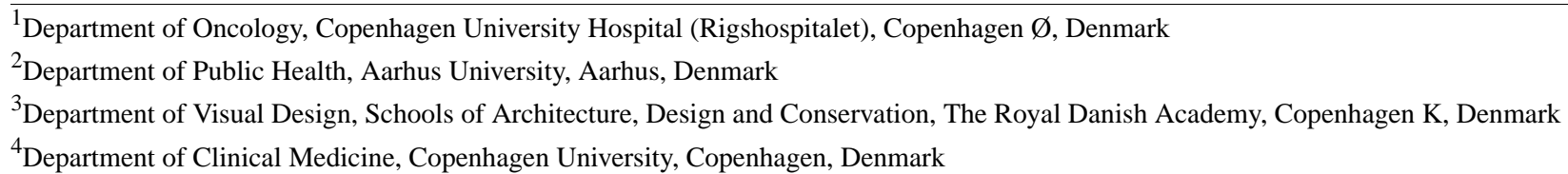

\section{Corresponding Author:}

Karin Piil, MSc, PhD

Department of Oncology

Copenhagen University Hospital (Rigshospitalet)

Blegdamsvej 9

Copenhagen Ø, 2100

Denmark

Phone: 4535450733

Email: Karin.piil@ regionh.dk

\begin{abstract}
Background: Most cancer treatments today take place in outpatient clinics; however, it might be necessary for some patients to be admitted to hospital departments due to severe side effects or complications. In such situations, support from family and social relations can be crucial for the patients' emotional well-being. Many young adolescents and children whose parents have cancer describe how they are not seen, heard, or listened to as the worried relatives they are. Within the intensive care unit, it has been recommended that early supportive interventions are tailored to include children of the intensive care patient; a similar approach might be relevant in the oncological setting. To our knowledge, no studies have explored how to involve young relatives who are visiting their parent at an oncological department. Recently, a framework for developing theory-driven, evidence-based serious games for health has been suggested. Such a process would include stakeholders from various disciplines, who only work toward one specific solution. However, it is possible that bringing together different disciplines, such as design, art, and health care, would allow a broader perspective, resulting in improved solutions.
\end{abstract}

Objective: This study aims to develop tools to enhance the social interaction between a parent with cancer and their child when the child visits the parent in the hospital.

Methods: In total, 4 groups of design students within the Visual Design program were tasked with developing games addressing the objective of strengthening relations in situ during treatment. To support their work, the applied methods included professional lectures, user studies, and visual communication (phase I); interviews with the relevant clinicians at the hospital (phase II), co-creative workshops with feedback (phase III), and evaluation sessions with selected populations (phase IV). The activities in the 4 phases were predefined. This modified user design had the child (aged 4-18 years) of a parent with cancer as its primary user.

Results: Overall, 4 different games were designed based on the same information. All games had the ability to make adults with cancer and their children interact on a common electronic platform with a joint goal. However, the interaction, theme, and graphical expression differed between the games, suggesting that this is a wide and fertile field to explore.

Conclusions: Playing a game can be an efficient way to create social interaction between a parent with cancer and a child or an adolescent, potentially improving the difficult social and psychological relations between them. The study showed that the development of serious games can be highly dependent on the designers involved and the processes used. This must be considered when a hospital aims to develop multiple games for different purposes. 
(JMIR Serious Games 2021;9(1):e16029) doi: 10.2196/16029

\section{KEYWORDS}

cancer patients; children; adolescents; social relation; emotional well-being; gamification; relatives; visual design; serious games

\section{Introduction}

Patients diagnosed with cancer often undergo aggressive oncological treatment mainly provided by outpatient clinics at hospitals [1]. The patients experience a wide range of changing symptoms that occur due to the cancer itself as well as side effects from the treatment [2]. Sometimes, there are complications, resulting in a potentially life-threatening situation for the patient, requiring admission to the hospital. The two main disadvantages of such situations are related. First, the patients may suffer due to being away from their family [3]. Second, patients find themselves in a distressing situation and are left alone with their concerns and worries. In these situations, patients benefit from receiving emotional and social support from their close relatives. Social support includes personal, informal advice, and can provide strength that helps individuals initiate and sustain self-management activities. Existing literature has identified a correlation between patients' perceived degree of social support and quality of life [4]. Further, children and adolescents with a parent with cancer have noted that they are not seen, heard, and listened to as the worried relative they are [5]. Few studies have explored the experiences of children and adolescents across a parent's illness trajectory; however, a recent meta-synthesis recommended early supportive interventions tailored to include the children of intensive care patients [6]. To our knowledge, no studies have explored how to include children who are visiting their parent at an oncological department. Still, there is a general acknowledgment that health care professionals need to reflect on how to approach children and young adolescents at the hospital when they are visiting a parent [5,7]. Gamification, serious gaming, and edutainment have the potential to establish enjoyable and motivating experiences when gaming elements are introduced in a nongaming context [8]. The notion of gamification and serious gaming is traditionally used to increase adherence to medication regimens, promote health education for patients, and offer apps for chronic disease management [9]. Video games and serious gaming have the ability to enchant and engage patients and their children in a different "world" and thus give them a collective short break from the otherwise rather serious context they are in together. We are not aware of other studies aimed at facilitating social and joyful interaction between a parent with cancer and their children through gamification during hospitalization in an oncological department. However, virtual emotional authenticity and feelings of empathy may be able to help patients with cancer frame the often traumatizing experiences in more positive terms [10]. The development of serious games for such purposes is, as in eHealth generally, based on scientific and design foundations [11]. However, the product developed for a given purpose might be dependent on the software provider, the processes, or the specific designer asked to address specific needs. By bringing together different disciplines and acknowledging the diversity in art and design, more solutions might be designed for the same purpose [12].
This study aims to develop tools to enhance social interaction between a parent with cancer and their children when the children visit the parent at the hospital.

\section{Methods}

\section{Overview}

This study is based on an interdisciplinary co-creation process with clinical oncology specialists from Copenhagen University Hospital (KP, HG, and HP), gaming and visual design experts from The Royal Danish Academy of Architecture, Design, and Conservation (TK, JK, and JJ), and second-year bachelor's degree students at the Academy. The study did not need ethical approval. For this study, over 3 months, 4 different groups of design students within the Visual Design program were tasked with developing games addressing the objectives of the field of design and focusing on strengthening relations in situ during treatment. This modified user-centered design had the child (aged 4-18 years) of a parent with cancer as its primary user. Target age groups were defined in the initial phases of the project based on statistical information from the department and the already established research focus of next of kin and young adults as relatives, as well as by established researchers from the field of developmental psychology and the complexity of the developed games [12]. We approached the target groups through the lens of media use, where a concrete game is part of the broader media ecology, meaning that material from a television series can cross into a video game, and a video game can cross into children's outdoor analog play [13]. This has a specificity that exceeds the level of detail offered by developmental psychology, and the guiding principle for design was therefore observations of the actual game and media use by children in the respective age brackets [13]. The activities in the 4 phases were structured and predefined.

\section{Phase I}

The clinical specialists presented the clinical settings and environment of the oncological department (eg, standard cancer disease and treatment trajectories) to the students, as well as the context of the study aim and ethical issues. The students signed a confidentiality agreement. Discussions on how to establish and strengthen social and joyful togetherness between the admitted parent with cancer and their children were facilitated. There was an underlying consideration of how to nurture the experience of social support that may play an important role in a multifaceted approach to preventing complicated grief among relatives. The hospital and its staff were defined as customers in the development process, and the field of developmental psychology was researched throughout the process [13]. 


\section{Phase II}

The students interviewed nurses $(n=4)$ who were selected to be informers due to their extensive experiences with patients with cancer and their relatives.

\section{Phase III}

Students listened to the story of a bereaved child from The Danish National Center for Grief. Students were given a lecture by a researcher with a special interest in and knowledge of children as relatives of parents with cancer [14]. Students could ask questions of and engage in discussions with both lecturers.

\section{Phase IV}

The students presented their initial prototypes and received feedback from the multidisciplinary team. Acceptability testing was performed in an external population; a class of healthy children from the same age group was used for this purpose.
Adjustments were incorporated ahead of an official presentation at the hospital and visitors at the prototype exhibition were randomly included in the usability test. Hence, the prototypes were tested for usability using this small, selected population via surveys. Tests of the prototypes with hospitalized parents with cancer and their children were not performed due to ethical considerations.

\section{Results}

In phases I-III, the facts used for the design process were documented in written reports by the 4 working groups. Information from interdisciplinary stakeholders such as patients, nurses, research specialists, clinical oncological specialists, and gaming and visual design experts was included as a design foundation for all reports. In phase IV, 4 independent prototype games were developed (Table 1). Each game included an acceptance test using nontarget populations.

Table 1. Prototypes of the games.

\begin{tabular}{|c|c|c|c|c|c|}
\hline Game title & Theme & $\begin{array}{l}\text { Target age } \\
\text { group (years) }\end{array}$ & Element of interaction & $\begin{array}{l}\text { How the game aims to cre- } \\
\text { ate social interaction }\end{array}$ & Number of players \\
\hline Fun and Cozy Socks & Good mood gaming & $15-18$ & $\begin{array}{l}\text { Sample of social and interac- } \\
\text { tive guessing minigame }\end{array}$ & $\begin{array}{l}\text { Establishes a feel-good } \\
\text { atmosphere with } \\
\text { competition and laughs }\end{array}$ & $2-3$ \\
\hline The Witch & $\begin{array}{l}\text { Magic team building } \\
\text { game }\end{array}$ & $4-8$ & $\begin{array}{l}\text { Cooperative multiplayer } \\
\text { game, book, and electronic } \\
\text { game }\end{array}$ & $\begin{array}{l}\text { Provides a fun and enjoyable } \\
\text { activity that builds trust be- } \\
\text { tween the players }\end{array}$ & 2 \\
\hline $\begin{array}{l}\text { Kurt, the Hospital } \\
\text { Cat }\end{array}$ & Augmented reality & $6-12$ & $\begin{array}{l}\text { The interactive experience } \\
\text { of a real-world environment } \\
\text { with a search for items in the } \\
\text { physical surroundings }\end{array}$ & $\begin{array}{l}\text { Adds information and } \\
\text { meaning to the hospital sur- } \\
\text { roundings }\end{array}$ & $\begin{array}{l}1 \\
\text { (includes the possibility } \\
\text { of interacting with a par- } \\
\text { ent in search for items) }\end{array}$ \\
\hline Bloom & $\begin{array}{l}\text { Growing a garden } \\
\text { and bringing it to } \\
\text { life }\end{array}$ & $4-18$ & Customization/minigames & $\begin{array}{l}\text { Makes the players feel good } \\
\text { and is enjoyable. Shows that } \\
\text { you care for a person by } \\
\text { growing flowers and taking } \\
\text { care of them. }\end{array}$ & $\begin{array}{l}1 \text { player on a social plat- } \\
\text { form }\end{array}$ \\
\hline
\end{tabular}

In general, the prototypes were highly accepted by age-equivalent testing groups. A usability test among random visitors at the parallel presentation of all 4 solutions included patients $(n=6)$, health care professionals $(n=10)$, and young adults $(n=3)$. The survey results included good ratings for "interesting game," "user friendly," and "willingness to use" in a hospital setting. In general, all solutions were positively evaluated, reflecting a fundamental interest in playing games to experience joyful moments. However, the older population (aged $>70$ years) seemed to have reduced digital competencies and a lower willingness to use such games.

The prototypes (Figure 1) were tested on a small, selected population via a paper-based survey. Physical contact testing was not possible due to ethical concerns.

Figure 1. Front pages for game prototypes.
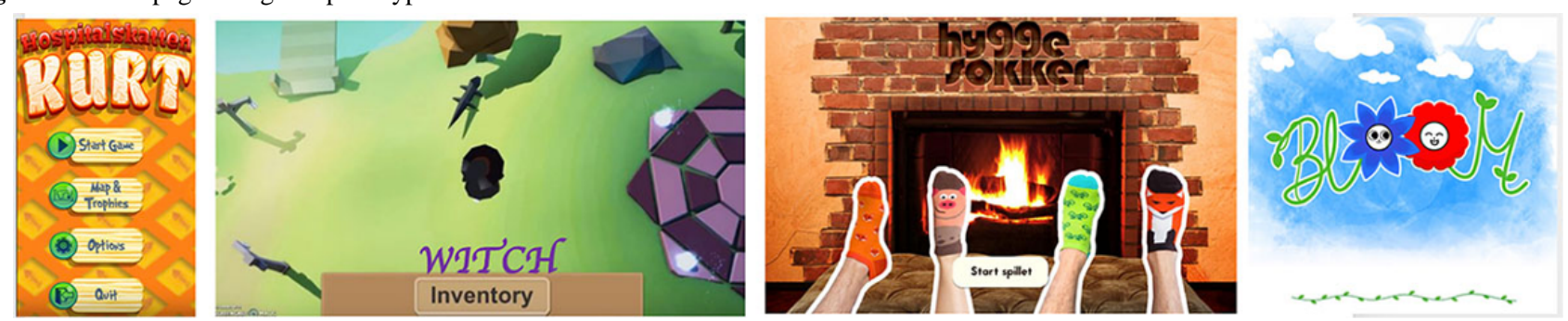


\section{Discussion}

\section{Principal Findings}

Based on the same information and evaluation, 4 different working groups skilled in visual design developed games with different themes and interactions, for different target age groups, to solve the same challenge. This study shows that gamification has the potential to solve newly revealed needs within health care, such as improving interactions between a parent with cancer and their child. This study suggests that several types of designs can solve the same problem, but also underscores that solutions are highly dependent on the software developer and designer. These factors should be considered when, for example, a hospital aims to develop multiple games for different purposes, or when the best game for a specific purpose is requested.

It has previously been described how patient and family involvement is valuable for health [15]; however, little is known about the involvement of children as relatives. In the adult setting, eHealth tools have been developed for adult relatives [16] to improve their psychological well-being, but not to improve their interactions with the patient. It is known that web-based tools and games can be used to improve adolescents' and young adults' adherence to vaccination programs and therapy $[17,18]$. It seems that eHealth tools can improve psychological outcomes [19]. It might be argued that the development of serious games for health should be based on a framework suggested by Verschueren et al [11]. However, to improve the quality of serious games for health, this study tries to encourage interdisciplinary cooperation between art and health science experts to elicit a greater number of suggestions of game-based solutions for the same purpose, followed by a selection of the best feasible solution for a specific need considering the different themes and graphic design elements of the developed games.

\section{Limitations}

A limitation of this study might be that the tools were developed by students; however, they were supervised by experts in gamification and evaluated and given continuous feedback during the process by user design and gamification experts.

A modified concept of user-centered design was applied to this tool developing process, where experiences from one young relative and other stakeholders were the basis for the development. However, this one representative was used to represent a group of children and young relatives of patients with cancer.

All 4 working groups performed an acceptance test of their product in a nonhospital environment (eg, a day care facility or school). The usability test involved the parallel testing of all 4 tools in a hospital environment and included children/young people, patients/relatives, and hospital staff. None of these tests were performed with a larger group of children who are relatives of patients with cancer; thus, the generalizability of the findings must be further explored.

\section{Conclusion}

A game can be an efficient method for fostering social interaction between a parent with cancer and a child or an adolescent, and games likely have the power to improve the difficult social and psychological relations between parents and children in this context. When creating games for specific purposes such as this, it must be remembered that games designed based on the same assignment might use different themes and graphic design elements, indicating that the development of serious games may be highly dependent on the designer involved. The described games remain to be investigated more thoroughly regarding their feasibility and efficacy in the context of qualitative oncological research. If shown to be feasible, implementation among patients with cancer and their relatives will be carried out.

\section{Acknowledgments}

Thanks to the students at The Royal Danish Academy of Architecture, Design, and Conservation for taking part in this study. Thanks to Annemarie Dencker, University of Southern Denmark, and The Danish National Center for Grief for participating in phase III.

\section{Conflicts of Interest}

None declared.

\section{References}

1. Borras J, Sanchez-Hernandez A, Navarro M, Martinez M, Mendez E, Ponton JL, et al. Compliance, satisfaction, and quality of life of patients with colorectal cancer receiving home chemotherapy or outpatient treatment: a randomised controlled trial. BMJ 2001 Apr 07;322(7290):826 [FREE Full text] [doi: 10.1136/bmj.322.7290.826] [Medline: 11290635]

2. Gegechkori N, Haines L, Lin JJ. Long-Term and Latent Side Effects of Specific Cancer Types. Med Clin North Am 2017 Nov;101(6):1053-1073 [FREE Full text] [doi: 10.1016/j.mcna.2017.06.003] [Medline: 28992854]

3. Robinson J, Gott M, Gardiner C, Ingleton C. The impact of the environment on patient experiences of hospital admissions in palliative care. BMJ Support Palliat Care 2018 Dec;8(4):485-492. [doi: 10.1136/bmjspcare-2015-000891] [Medline: 26408427]

4. Piil K, Jakobsen J, Christensen K, Juhler M, Guetterman T, Fetters M, et al. Needs and preferences among patients with high-grade glioma and their caregivers - A longitudinal mixed methods study. Eur J Cancer Care (Engl) 2018 Mar;27(2):e12806. [doi: 10.1111/ecc.12806] [Medline: 29314470] 
5. Golsäter M, Henricson M, Enskär K, Knutsson S. Are children as relatives our responsibility? - How nurses perceive their role in caring for children as relatives of seriously ill patients. Eur J Oncol Nurs 2016 Dec;25:33-39. [doi: 10.1016/j.ejon.2016.09.005] [Medline: 27865250]

6. MacEachnie LH, Larsen HB, Egerod I. Children's and young people's experiences of a parent's critical illness and admission to the intensive care unit: A qualitative meta-synthesis. J Clin Nurs 2018 Aug;27(15-16):2923-2932. [doi: 10.1111/jocn.14498] [Medline: 29700880]

7. Prevention of complicated grief reactions in children, youth, adults and elderly people following an expected or unexpected death of a significant other/close relative. Center for Clinical Guidelines. 2018. URL: https://tinyurl.com/y2kfge4t [accessed 2019-06-01]

8. Abdul Rahim MI, Thomas RH. Gamification of Medication Adherence in Epilepsy. Seizure 2017 Nov;52:11-14 [FREE Full text] [doi: 10.1016/j.seizure.2017.09.008] [Medline: 28934624]

9. Miller AS, Cafazzo JA, Seto E. A game plan: Gamification design principles in mHealth applications for chronic disease management. Health Informatics J 2016 Jun;22(2):184-193 [FREE Full text] [doi: 10.1177/1460458214537511] [Medline: 24986104]

10. Bowman A. Companionship Games: A Framework for Emotionally Engaging and Empathetic Interactive Characters. In: Interactive storytelling: 12th International Conference on Interactive Digital Storytelling, ICIDS 2019, Little Cottonwood Canyon, UT, USA, November 19-22, 2019, Proceedings.: Springer; 2019 Presented at: 12th International Conference on Interactive Digital Storytelling; November 19-22, 2019; Little Cottonwood Canyon, UT, USA p. 413-417. [doi: 10.1007/978-3-030-33894-7_44]

11. Stirbis PP, Sakalauskas II. [Electrostimulation of the interatrial septum]. Kardiologiia 1984 Dec;24(12):11-14. [Medline: 6521217]

12. Buchanan R. Wicked Problems in Design Thinking. Design Issues 1992;8(2):5-21. [doi: 10.2307/1511637]

13. Giddings S. Gameworlds: Virtual Media and Children's Everyday Play. New York, NY, USA: Bloomsbury Academic; 2014:17-137.

14. Dencker A, Kristiansen M, Rix BA, Bøge P, Tjørnhøj-Thomsen T. Contextualisation of patient-centred care: A comparative qualitative study of healthcare professionals' approaches to communicating with seriously ill patients about their dependent children. Eur J Cancer Care (Engl) 2018 Jan;27(1). [doi: 10.1111/ecc.12792] [Medline: 29114990]

15. Prior S, Campbell S. Patient and Family Involvement: A Discussion of Co-Led Redesign of Healthcare Services. J Particip Med 2018 Feb 01;10(1):e5 [FREE Full text] [doi: 10.2196/jopm.8957] [Medline: 33052119]

16. Köhle N, Drossaert CH, Oosterik S, Schreurs KM, Hagedoorn M, van Uden-Kraan CF, et al. Needs and Preferences of Partners of Cancer Patients Regarding a Web-Based Psychological Intervention: A Qualitative Study. JMIR Cancer 2015 Dec 29;1(2):e13 [FREE Full text] [doi: 10.2196/cancer.4631] [Medline: 28410157]

17. Eley CV, Young VL, Hayes CV, Verlander NQ, McNulty CAM. Young People's Knowledge of Antibiotics and Vaccinations and Increasing This Knowledge Through Gaming: Mixed-Methods Study Using e-Bug. JMIR Serious Games 2019 Feb 01;7(1):e10915 [FREE Full text] [doi: 10.2196/10915] [Medline: $\underline{\text { 30707096] }}$

18. Castel AD, Qasmieh S, Greenberg D, Ellenberger N, Howell TH, Griffith C, et al. Digital Gaming to Improve Adherence Among Adolescents and Young Adults Living With HIV: Mixed-Methods Study to Test Feasibility and Acceptability. JMIR Serious Games 2018 Oct 15;6(4):e10213 [FREE Full text] [doi: 10.2196/10213] [Medline: 30322838]

19. Primack B, Carroll MV, McNamara M, Klem ML, King B, Rich M, et al. Role of video games in improving health-related outcomes: a systematic review. Am J Prev Med 2012 Jun;42(6):630-638 [FREE Full text] [doi: 10.1016/j.amepre.2012.02.023] [Medline: 22608382]

Edited by N Zary; submitted 05.09.19; peer-reviewed by S Brigitte, G Meinlschmidt; comments to author 26.10.20; revised version
received 23.11.20; accepted 08.01.21; published 21.01.21
Please cite as:
Piil K, Gyldenvang HH, Mфller JK, Kjoelsen T, Juul J, Pappot H
Electronic Games for Facilitating Social Interaction Between Parents With Cancer and Their Children During Hospitalization:
Interdisciplinary Game Development
JMIR Serious Games $2021 ; 9(1):$ e16029
URL: $\underline{\text { http://games.jmir.org/2021/1/e16029/ }}$
doi: $\underline{10.2196 / 16029}$
PMID: $\underline{33475523}$

CKarin Piil, Helle Holm Gyldenvang, Jeppe Kilberg Møller, Tine Kjoelsen, Jesper Juul, Helle Pappot. Originally published in JMIR Serious Games (http://games.jmir.org), 21.01.2021. This is an open-access article distributed under the terms of the Creative Commons Attribution License (https://creativecommons.org/licenses/by/4.0/), which permits unrestricted use, distribution, and 
reproduction in any medium, provided the original work, first published in JMIR Serious Games, is properly cited. The complete bibliographic information, a link to the original publication on http://games.jmir.org, as well as this copyright and license information must be included. 